\title{
Diabetics blood glucose control based on GA-FOPID technique
}

\author{
Wesam M. Jasim ${ }^{1}$, Yousif I. Al Mashhadany ${ }^{2}$ \\ ${ }^{1}$ College of Computer Science and Information Technology, University of Anbar, Iraq \\ ${ }^{2}$ Department of Electrical Engineering, College of Engineering, University of Anbar, Iraq
}

\begin{tabular}{l}
\hline \hline Article Info \\
\hline Article history: \\
Received Apr 13, 2020 \\
Revised Jun 29, 2020 \\
Accepted Jul 30, 2020 \\
\hline
\end{tabular}

Keywords:

Diabetic system

Fractional order PID

GA-FOPID

Genetic algorithm

\begin{abstract}
In this paper, an optimized Fractional Order Proportional, Integral, Derivative based Genetic Algorithm GA-FOPID optimization technique is proposed for glucose level normalization of diabetic patients. The insulin pump with diabetic patient system used in the simulation is the Bergman minimal model, which is used to simulate the overall system. The main purpose is to obtain the optimal controller parameters that regulate the system smoothly to the desired level using GA optimization to find the FOPID parameters. The next step is to obtain the FOPID controller parameters and the traditional PID controller parameters normally. Then, the simulation output results of using the proposed GA-FOPID controller was compared with that of using the normal FOPID and the traditional PID controllers. The comparison shows that all the three controllers can regulate the glucose level but the use of GA-FOPID controller was outperform the use of the other two controllers in terms of speed of normalization and the overshoot value.
\end{abstract}

This is an open access article under the CC BY-SA license.

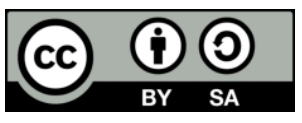

\section{Corresponding Author:}

Wesam M. Jasim,

College of Computer Science and Information Technology,

University of Anbar, Iraq.

Email: co.wesam.jasim@uoanbar.edu.iq

\section{INTRODUCTION}

Diabetes is not a newborn disease; it has been with civilization from a long time. It affects more than 400 million adults worldwide and causes about two million deaths. Diabetes is a malady in which the blood glucose levels are too high. Aldohexose comes from some type of foods. Internal secretion may be a hormone that helps the aldohexose gets into cells to offer them energy. With sort one polygenic disease, the human body doesn't build internal secretion. With sort a pair of polygenic disease, the additional common sort, the body doesn't build or use internal secretion well. While not enough internal secretion, the aldohexose stays in body blood. The human body will even have prediabetes. This means that blood glucose is higher than conventional, however not high enough to be known as polygenic disease. Having prediabetes puts the human at the next risk of obtaining sort a pair of polygenic disease [1-3].

Over time, having an excessive amount of aldohexose in human body blood will cause serious problems. It will harm eyes, kidneys, and nerves. Gene disease may also cause cardiovascular disease, stroke and even the necessity to get rid of a limb. Pregnant ladies may also develop a multi-gene disease, known as physiological condition polygenic disease. Diabetes mellitus or diabetes has been divided in to four types; type 1 , type 2 , gestational diabetes, and some specific types. These specific types are several individual causes with different conditions and treatment. Diabetes may be a lot of variable malady than once thought and people could have mixtures of forms. The main therapy used for type 1 diabetes is the insulin injections to keep the blood glucose level within the normal level $[1,4]$. 
Nowadays, the engineers designed a medical device to pump the insulin into the patient body called the insulin pump of the closed loop block diagram shown in Figure 1. The main part in this device is the design of a suitable controller for the pump [5]. This work is focused in the designing of a GA-FOPID controller. In last decay, many researchers have been studies several control algorithms to control the blood glucose level of type 1 patients based on the insulin pump device. Most of these algorithms were based on the PID control algorithm as it is easy to implement practically. The major difference was the tuning method which leads to improve the efficiency response of the insulin pump in terms of speed, low over shoot and root mean square error. A digital PID controller was main control algorithm discussed in literature. For example, authors in [2] designed a digital PID controller based on Ziegler-Nichols and Cohen-Coon tuning techniques. While the digital PID controller was proposed to control the blood glucose level of a diabetic patient in [6]. Several tuning techniques were used to find the controller parameter coefficients such as, Astrom-Hagglund, Cohen-Coon, and Chien-Hrones-Reswick techniques. The digital PID controller was implemented via Field Programmable Gate Array device to control the patient glucose level. The controller parameters were tuned based on Zeigler-Nichols technique [7].

Another proposed control technique to control the patient glucose level was the intelligent control algorithms such as, the fuzzy control algorithm proposed in [5]. A linearly decreasing weight particle swarm optimization method was used for four tests for type 1 patients. The meal disturbance was considered with the parameter uncertainties to show the robustness of the proposed controller. The simulation results verified that the proposed algorithm was outperforming the other controller. In [4] a FOPID controller was proposed for a nonlinear model of type 1 diabetes with patient up normal conditions to regulate the insulin level. The results show that the use of FOPID controller performs better than the use of normal PID controller. Optimization method was used for four tests for type 1 patients. The meal disturbance was considered with the parameter uncertainties to show the robustness of the proposed controller. The simulation results verified that the proposed algorithm was outperforming the other controller. A fuzzy-PID control algorithm was implemented for automatic insulin transfer system in [8]. The obtained results were compared with that of the fuzzy-PD, fuzzy-PI and reference model controllers. It shows that the proposed controller was kept the insulin for longer time than the other controllers. In [9] two controllers were developed to regulate the insulin level in a type 1 patient, the PID and fuzzy controllers. In [10] a genetic fuzzy PI controller was applied to linearized type 1 diabetes using the gap metric to regulate the patient sugar level. The genetic algorithm was used to tune the fuzzy memberships. The simulation results demonstrate that the proposed controller has given a significant improvement over the conventional PI controller in terms of overshoot and fast response.

The nonlinear control algorithms such as, backstepping [11], backstepping with sliding mode [12], integral backstepping [13], adaptive controller with parametric compansation [14], and multi objective with $\mathrm{H} \infty$ [15] were designed to control the type 1 patient blood sugar level to deal with the nonlinear part of the dynamic model. In [16] a $\mathrm{H} \infty$ control algorithm was proposed to normalize the diabetes glucose level to meet the stability and robustness conditions of the system with known meal disturbance consideration. In [17] an internal model and PD controllers were discussed to normalize the glucose level. In [18] a single network adaptive critic was proposed to regulate the blood sugar level and its results were compared with that of linear quadratic regulator. A robust control strategy based on linear matrix inequality, extended kalman filter, tensor product model transformation and parameter varying approaches were proposed in [19] to solve the type 1 diabetes control problem with control constraints guaranteed.

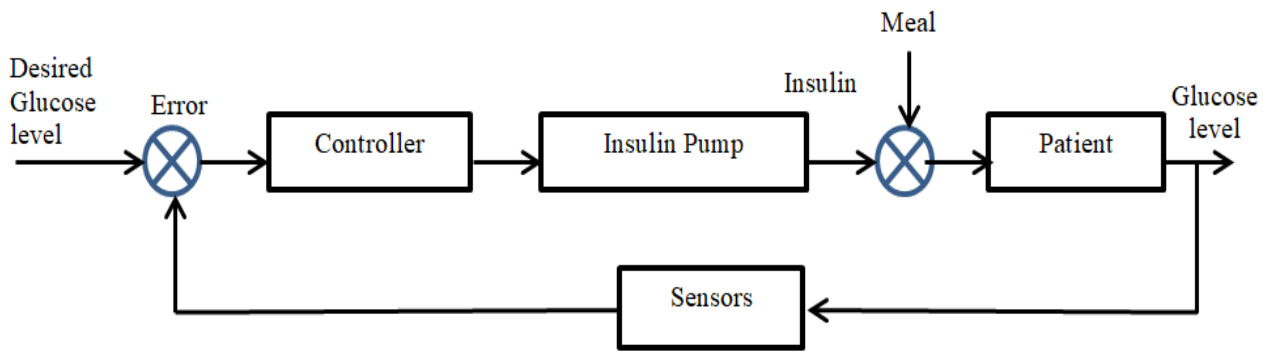

Figure 1. Insulin pump control diagram

In [20] the authors were designed an artificial pancereas which controlled based on model predictive control technique. The simulation results show a significant regulation accuracy compared with the existing results. Combinations of three control techniques were proposed to control the pariant blood glucose system in [21]. These techniques were; the fuzzy logic, fractional order, and sliding mode control techniques. In [22] 
the authors found few researchers in the literature they proposed the reinforcement learning approach to control the blood glucose system. In conclusions, the responses of the above controllers were had a significant overshoot which affects the patient himself and the amount of the insulin injected to the human body. In this work, after analyzing and scrutinizing the results of previous traditional controllers (PID and FOPID), it is suboptimal result, therefore we use a technique (genetic algorithm) based on the sensitivity of the control signal level of the insulin pump apparatus on the basis of full knowledge of the properties of insulin injections. Our contribution is the enhancement of the FOPID controller to be optimized based on the GA. This method is optimized the controller parameters automatically and more accurately than the traditional trial and error method or the others. To evaluate the proposed controller performance, we also compare its results with that of the two traditional PID and FOPID controllers' results. The comparisons are illustrated in MATLAB simulation tests.

The rest of the paper is organized as follows; the mathematical model of the insulin pump is derived in section 2. Section 3 shows the mathematical description of the fractional order controller design combined with the genetic algorithm technique used for tuning purpose. In section 4 the controllers' implementation were compared. In section 5 the simulation results were illustrated and discussed. The conclusions and the future works were shown in sections 6 and 7 respectively.

\section{MATHEMATICAL MODEL}

The modeling description of the physical parameters in insulin pump device with the patient, the Bergman minimal mathematical model is used as in (1-3) [11, 14].

$$
\begin{aligned}
& \dot{G}(t)=-p_{1}\left[G(t)-G_{b}\right]-X(t) G(t)+D(t) \\
& \dot{X}(t)=-p_{2} X(t)+p_{3}\left[I(t)-I_{b}\right] \\
& \dot{I}(t)=-n\left[I(t)-I_{b}\right]+\gamma[G(t)-h]^{+} t+u(t)
\end{aligned}
$$

Where the parameters descriptions are illustrated in Table 1 [11].

Using the forward Laplace transform with neglecting the internal regulatory term $\gamma[\mathrm{G}(\mathrm{t})-\mathrm{h}]^{+}$and the disturbance term, (1-3) can be described in the form:

$$
\begin{aligned}
& s G(s)=-p_{1} G(s)-G_{b} X(s) \\
& s X(s)=-p_{2} X(s)+p_{3} I(s) \\
& s I(s)=-n I(s)+u(s)
\end{aligned}
$$

Table 1. Bergman model parameters

\begin{tabular}{cll}
\hline Symbol & \multicolumn{1}{c}{ Specification } & \multicolumn{1}{c}{ Normal value/units } \\
\hline $\mathrm{G}(\mathrm{t})$ & Concentration of plasma glucose & $\mathrm{mg} / \mathrm{dL}$ \\
$\mathrm{p}_{1}$ & Insulin constant & $0.155^{*} 10^{-3} 1 / \mathrm{min}$ \\
$\mathrm{G}_{\mathrm{b}}$ & Glucose level before injection & $70 \mathrm{mg} / \mathrm{dL}$ \\
$\mathrm{X}(\mathrm{t})$ & Concentration of remote insulin & $\mathrm{mU} / \mathrm{L}$ \\
$\mathrm{D}(\mathrm{t})$ & Disturbance & $--.421 / \mathrm{min}$ \\
$p_{2}$ & Decrease rate of tissue's glucose up taking & $4.92^{*} 10^{-6}(\mu \mathrm{U} / \mathrm{ml}) / \mathrm{min}^{2}$ \\
$\mathrm{p}_{3}$ & Capacity of glucose up taking & $\mathrm{mU} / \mathrm{dL}$ \\
$\mathrm{I}(\mathrm{t})$ & Concentration of insulin in plasma & $7 \mu \mathrm{U} / \mathrm{ml}$ \\
$\mathrm{I}_{\mathrm{b}}$ & Insulin level before injection & $0.2651 / \mathrm{min}$ \\
$\mathrm{N}$ & Insulin in plasma decay rate & $0.0039 \mu \mathrm{U} / \mathrm{ml} / \mathrm{min}^{2} /(\mathrm{mg} / \mathrm{dL})$ \\
$\gamma$ & Body insulin secretion & $79.035 \mathrm{mg} / \mathrm{dL}$ \\
$\mathrm{H}$ & Glucose threshold & $\mathrm{mU} / \mathrm{min}$ \\
\hline $\mathrm{u}(\mathrm{t})$ & Insulin input &
\end{tabular}

In (6) can be rewritten as:

$$
I(s)=\frac{u(s)}{s+n}
$$

Substituting (7) into (5) we get: 


$$
X(s)=p_{3} u(s) /(s+n)\left(s+p_{2}\right)
$$

Substituting (8) into (4) we obtain:

$$
G(s)=-\frac{G_{b} p_{3} u(s)}{(s+n)\left(s+p_{2}\right)\left(s+p_{1}\right)}
$$

Then, the overall transfer function can be written as:

$$
\begin{aligned}
\frac{G(s)}{u(s)}=-\frac{G_{b} p_{3}}{(s+n)\left(s+p_{2}\right)\left(s+p_{1}\right)} & -G_{b} p_{3} \\
= & \frac{s^{3}+\left(n+p_{1}+p_{2}\right) s^{2}+\left(p_{1} p_{2}+p_{1} n+p_{2} n\right) s+p_{1} p_{2} n}{}
\end{aligned}
$$

Now, using the parameter values in Table 1, the transfer function in (10) can be written as:

$$
\frac{G(s)}{u(s)}=\frac{-0.3444 * 10^{-3}}{s^{3}+0.6852 s^{2}+11.14 * 10^{-2} s+0.1725 * 10^{-6}}
$$

\section{CONTROLLER DESIGN}

\subsection{FOPID controller}

The FOPID approach of the form $\mathrm{PI}^{\beta} \mathrm{D}^{\rho}$ illustrated in (12) is proposed in this work to improve the normalization of the glucose level in the diabetic patient by control the insulin pump device described in Figure 1 and the transfer function in (11).

$$
P I^{\beta} D^{\rho}=K_{p}+\frac{K_{I}}{S^{\beta}}+K_{D} S^{\rho}
$$

If the difference between the measured glucose level and the reference or the glucose desired level is the error input to the proposed control is $\mathrm{e}(\mathrm{t})$, then, the controller output or the insulin pump input is:

$$
u(t)=K_{P} e(t)+K_{I} D^{-\beta} e(t)+K_{D} D^{\rho} e(t)
$$

where, $\mathrm{D}$ is the fractional operator, $\mathrm{K}_{\mathrm{P}}, \mathrm{K}_{\mathrm{I}}, \mathrm{K}_{\mathrm{D}}, \beta$, and $\rho$ are the constant proportional, integral, derivative, integral part order, and derivative part order controller parameters. It is obvious that if the values of $\beta$ and $\rho$ are chosen equal to 1, then the obtained controller is a traditional PID controller. If the first one is chosen as 1 and the second is chosen as 0 , then the obtained controller is a traditional PI controller. In contrast, if the first one is chosen as 0 and the second is chosen as 1 , then the obtained controller is a traditional PD controller. The main objective is to enhance the control performance of the overall system by finding optimal controller parameters. The genetic algorithm approach is proposed in this work to optimize the controller parameters.

\subsection{Genetic algorithm}

GA is suggested in this work to optimize the FOPID controller parameters. The MATLAB GA toolbox version $2018 \mathrm{~b}$ is used for the tuning purpose. GA is a random search mechanism technique used for solving the optimization problems. It employments probabilistic rules rather than deterministic rules and manages a populace of potential arrangements known as chromosomes that advance iteratively. Each emphasis of the calculation is named an era. The advancement of arrangements is mimicked through a wellness work and hereditary administrators such as population, crossover, and mutation. The algorithm is started with random population usually in a binary string or real number named chromosome. It is performance is measured by a chosen objective function named fitness. The error is used to estimate the fitness of the chromosomes [23], [24]. Optimization based on GA is beginning with the parameters generation (chromosomes), then the fitness of these parameters are calculated. In the next step, a new generation (children) are produced, this step are repeated in all iterations of the algorithm [25-26]. Figure 2 shows the GA steps [27]. 


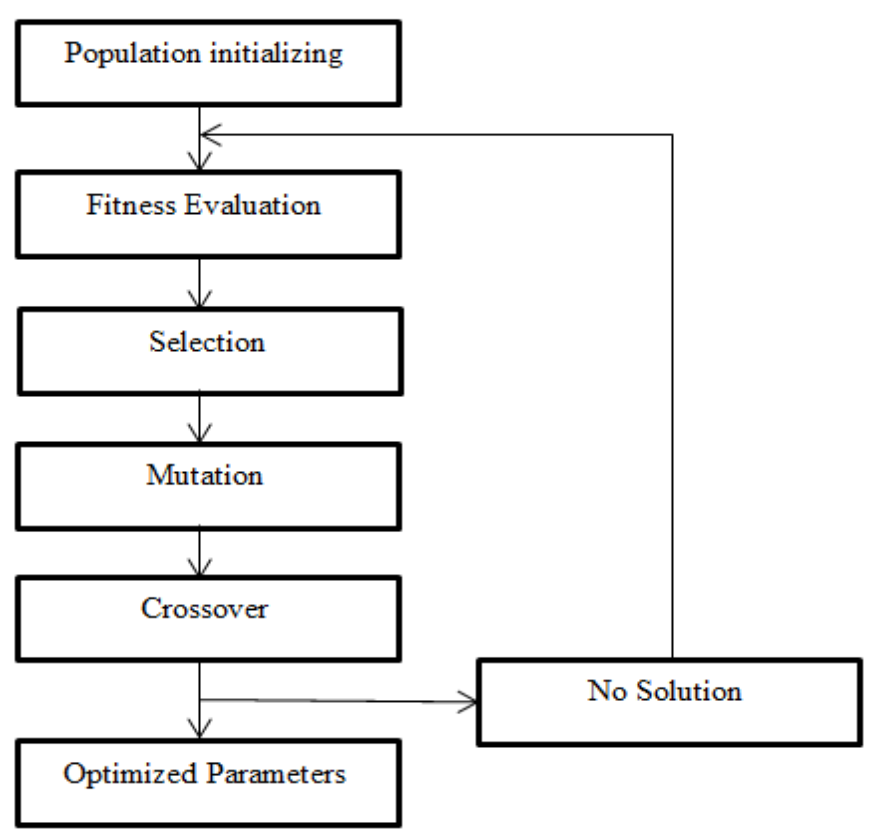

Figure 2. The genetic algorithm flow chart

\subsection{GA-FOPID}

The FOPID controller parameters tuning based on genetic optimization algorithm steps are; the first step is to initialize a small population size named chromosomes to find the optimal controller parameters as fast as possible. Each chromosome has a fitness represents the controller parameters. In the second step all the controller parameters are transferred to the original controller at each iteration sample. Then the response of the system computed using an IAE cost function. These steps are repeated until the minimum objective function-fitness-value is obtained. Finally, the final controller parameters are obtained to be used in the original system.

\section{CONTROLLER COMPARISON}

For more materialization the proposed GA-FOPID controller response, a comparison with the classical PID and FOPID controllers' response for the diabetics' blood glucose problem is illustrated in this section. It is clear that the finding of the proposed GA-FOPID controller parameters is automated and it is easier to obtain than that of the two classical PID and FOPID controllers' parameters, which obtained via a classical manner. Moreover, finding these classical controllers' parameters required long time and greater potential. The obtained results show that the response of the proposed GA-FOPID controller is significant faster than the other two controllers. It is also clear that the GA-FOPID controller leads to a smoother response compared with that of the other controllers. More details about the simulation tests are explained in the simulation results section.

\section{SIMULATION RESULTS}

In this section the simulation of the diabetic system which includes the insulin pump device and the patient with FOPID $\mathrm{PI}^{\wedge} \beta \mathrm{D}^{\wedge} \rho$ based GA tuning technique was implemented using MATLAB $2018 \mathrm{~b}$ combined with the FOMCON toolbox such that the step time response of the closed loop system shown in Figure 1 is closed to the reference input. The original closed loop system step response is shown in Figure 3. It is clear that from Figure 3 the system is unstable and it is important to find a suitable controller to force the blood glucose to the desied level. Therefore; our aim is to stabilize the overall system with testing input. A comparison among three control techniques PID, FOPID, and GA-FOPID were obtained, the results were shown in Table 2. The step responses of the closed loop control system using these controller parameters were shown in Figure 4. The system was tested using a hard testing signal shown in Figure 5 with their response. It is obvious that the response of the system using the GA-FOPID controller was faster than the 
other two controllers to reach the desired level with no overshoot or steady state error. Moreover, the response of normal FOPID controller was outperforming the response of using the traditional PID controller.

Table 2. Controllers' parameters

\begin{tabular}{cccc}
\hline Parameter & GA-FOPID & PID & FOPID \\
\hline $\mathrm{K}_{\mathrm{P}}$ & 9.99 & 8 & 7 \\
$\mathrm{~K}_{\mathrm{I}}$ & 9.99 & 0.001 & 5 \\
$\mathrm{~K}_{\mathrm{D}}$ & 10 & 8 & 5 \\
$\beta$ & 0.0035 & --- & 0.01 \\
$\rho$ & 0.99 & --- & 1.9 \\
\hline
\end{tabular}

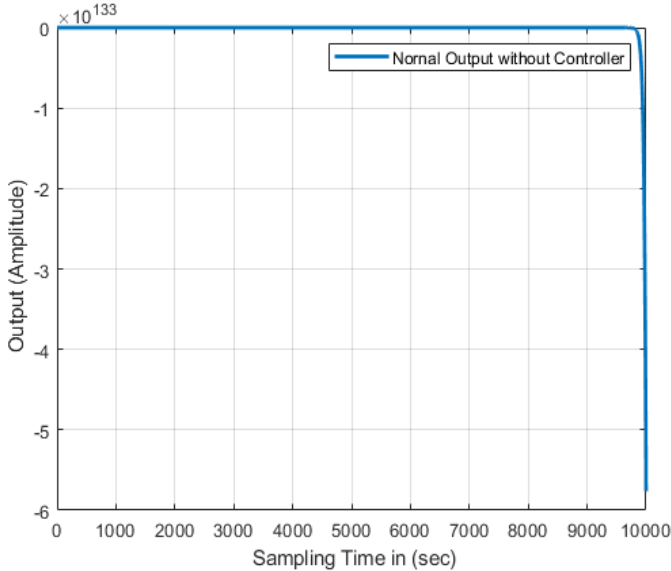

Figure 3. System step response without controller

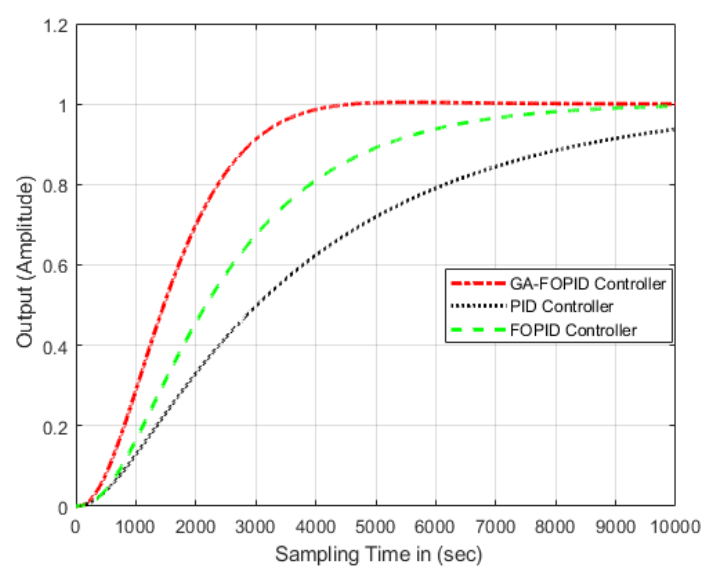

Figure 4. step response using different controllers

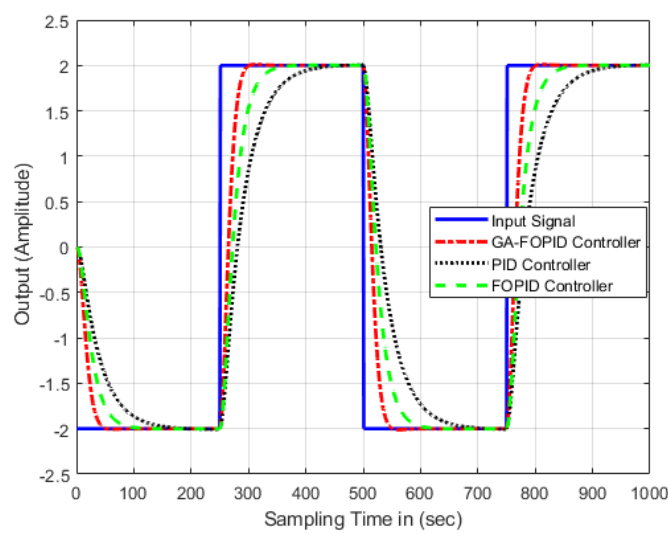

Figure 5. System response using different controllers

\section{CONCLUSION}

A complete insulin normalization system called Bergman model was implemented and controlled using a proposed GA-FOPID controller. The parameters of the controller were tuned using a genetic algorithm. The model was tested using the proposed GA-FOPID controller. Then, the system was tested using the normal FOPID and traditional PID controllers. There are some important different between the step responses among the three controllers tested in this paper. These differences were outcomes based on the different in tuning methods of the controllers' parameters. The performance of the use of the proposed GAFOPID based genetic algorithm tuning was outperforms the other two controllers' responses. Our future work towards this subject is to consider the effect of the disturbances (meals) and the model uncertainties in the control system. 


\section{FUTURE WORK}

One of the most important future works, which can be implemented with a complete insulin normalization system, is applying other control systems to obtain better results in terms of speed and stability in the system performance. An example of a control system that can be tried is the hybrid control system between the fuzzy systems and the modified PID systems. In the future, the proposed control system can be practically implemented as it is characterized by optimal response and can achieve advanced results in practical performance.

Literature review that has been done author used in the chapter "Introduction" to explain the difference of the manuscript with other papers, that it is innovative, it are used in the chapter "Research Method" to describe the step of research and used in the chapter "Results and Discussion" to support the analysis of the results [2]. If the manuscript was written really have high originality, which proposed a new method or algorithm, the additional chapter after the "Introduction" chapter and before the "Research Method" chapter can be added to explain briefly the theory and/or the proposed method/algorithm [4].

\section{REFERENCES}

[1] World Health Organization. "Global report on diabetes," WHO Library Cataloguing-in-Publication Data, 2016.

[2] R. Sharma, S. Mohanty and A. Basu, "Tuning of digital PID controller for blood glucose level of diabetic patient," 2016 IEEE International Conference on Recent Trends in Electronics, Information \& Communication Technology (RTEICT), Bangalore, pp. 332-336, 2016.

[3] Shuhada Mohd Rosli, Marshima Mohd Rosli, and Rosmawati Nordin, "A mapping study on blood glucose recommender system for patients with gestational diabetes mellitus," Bulletin of Electrical Engineering and Informatics, vol. 8, no. 4, pp. 1489-1495, Dec 2019.

[4] M. Goharimanesh, A. Lashkaripour, and A. Abouei Mehrizi, "Fractional order PID controller for diabetes patients," Journal of Applied Mechanics (JAMECH), vol. 46, no. 1, pp. 69-76, Jan 2015.

[5] M. H. Khooban, D. N. M. Abadi, A. Alfi, and M. Siahi, "Swarm optimization tuned mamdani fuzzy controller for diabetes delayed model," Turkish Journal of Electrical Engineering and Computer Sciences, vol. 21, pp. 2110-2126, 2013

[6] R. Sharma, S. Mohanty and A. Basu, "Improvising tuning techniques of digital PID controller for blood glucose level of diabetic patient," 2016 International Conference on Emerging Trends in Electrical Electronics \& Sustainable Energy Systems (ICETEESES), Sultanpur, pp. 159-163, 2016.

[7] Anilkumar V, R. Phadke, "Design of digital PID controller for blood glucose monitoring system," International Journal of Engineering Research and Technology (IJERT), vol. 3, no. 12, pp. 307-311, Dec 2014.

[8] M. Al-Fandi, M. A. Jaradat and Y. Sardahi, "Optimal PID-Fuzzy Logic Controller for type 1 diabetic patients," 2012 8th International Symposium on Mechatronics and its Applications, Sharjah, pp. 1-7, 2012.

[9] D. K. Nadar, and J. A. Talati, "Modeling of patient of type 1 diabetes for blood glucose control," International Journal of Scientific Research in Science Engineering and Technology (IJSRSET), vol. 2, no. 1, pp. 336-340, 2016.

[10] M. Goharimanesh, A. Lashkaripour, Sh. Shariatnia, and A. Akbari, "Diabetic control using genetic fuzzy-PI controller," International Journal of Fuzzy Systems, vol. 16, no. 2, pp. 133-139, June 2014.

[11] Faiz-Ul-Hassan, M. Adil, A. Khaqan, S. Shuja, M. I. Tiwana, Qadeer-ul-hassan, Sh. Malik, and R. A. Riaz, "Closed loop blood glucose control in diabetics," Biomedical Research, vol. 28, no. 16, pp. 7239-7236, 2017.

[12] N. T. Parsa, A. R. Vali, and R. Ghasemi, "Back stepping sliding mode control of blood glucose for type I diabetes," International Journal of Energy and power Engineering, vol. 8, no. 11, pp. 721-725, 2014.

[13] S. A. Babar, I. A. Rana, M. Arslan and M. W. Zafar, "Integral Backstepping Based Automated Control of Blood Glucose in Diabetes Mellitus Type 1 Patients," in IEEE Access, vol. 7, pp. 173286-173293, 2019.

[14] A. Nath, D. Deb, R. Dey and S. Das, "Blood glucose regulation in type 1 diabetic patients: an adaptive parametric compensation control-based approach," in IET Systems Biology, vol. 12, no. 5, pp. 219-225, 102018.

[15] S. Mandal and A. Sutradhar, "Robust multi-objective blood glucose control in Type-1 diabetic patient," in IET Systems Biology, vol. 13, no. 3, pp. 136-146, 62019.

[16] A. Mourad, G. Keltoun, and H. Aicha, "Blood glucose regulation in diabetics using Hळ control techniques," European Journal of Advances in Engineering and Technology, vol. 2, no. 5, pp. 1-6, 2015.

[17] N. Sivaramakrishnan, S. K. Lakshmanaprabu, and M. V. Muvvala, "Optimal model based control for blood glucose insulin system using continuous glucose monitoring," Journal of Pharmaceutical Sciences and Research, vol. 9, no. 4, pp. 465-469, 2017.

[18] Sk. F. Ali, and R. Padhi, "Optimal blood glucose regulation of diabetic patients using single network adaptive critics," Optimal Control Application and Methods, 2011.

[19] L. Kovács, G. Eigner, M. Siket and L. Barkai, "Control of Diabetes Mellitus by Advanced Robust Control Solution," in IEEE Access, vol. 7, pp. 125609-125622, 2019.

[20] C. Crecil Dias, S. Kamath and S. Vidyasagar, "Blood glucose regulation and control of insulin and glucagon infusion using single model predictive control for type 1 diabetes mellitus," IET Systems Biology, vol. 14, no. 3, pp. 133-146, 2020.

[21] Heydarinejad, H., Delavari, H. \& Baleanu, D, "Fuzzy type-2 fractional Backstepping blood glucose control based on sliding mode observer," International Journal of Dynamics and Control, vol. 7, pp. 341-354, 2019. 
[22] Tejedor M, Woldaregay AZ, Godtliebsen F, "Reinforcement Learning Application in Diabetes Blood Glucose Control: A Systematic Review," Artificial Intelligence InMedicine, vol 104, p. 101836, 2020.

[23] A. Jayachitra, and R. Vinodha. "Genetic algorithm based PID controller tuning approach for continuous stirred tank reactor," Advances in Artificial Intelligence, vol. 2014, pp. 1-8, 2014.

[24] Leila Mohammadian, Ebrahim Babaei, and Mohammad Bagher Bannae Sharifian, "H-GA-PSO Method for Tuning of a PID Controller for a Buck-Boost Converter Modeled with a New Method of Signal Flow Graph Technique," Bulletin of Electrical Engineering and Informatics, vol. 4, no. 1, pp. 32-42, March 2015.

[25] A. Ghasempour and M. B. Menhaj, "A new genetic based algorithm for channel assignment problem," Computational Intelligence, Theory and Applications, Ed. B. Reusch, Berlin: Springer, pp. 85-91, 2006.

[26] A. Ghasempour, "Using a genetic-based algorithm to solve the scheduling optimization problem for long-range molecular communications in nanonetworks," 2015 IEEE 26th Annual International Symposium on Personal, Indoor, and Mobile Radio Communications (PIMRC), Hong Kong, pp. 1825-1829, 2015.

[27] Sariffuddin Harun, and Mohd Faisal Ibrahim, "A genetic algorithm based task scheduling system for logistics service robots," Bulletin of Electrical Engineering and Informatics, vol. 8, no. 1, pp. 206-213, March 2019.

\section{BIOGRAPHIES OF AUTHORS}

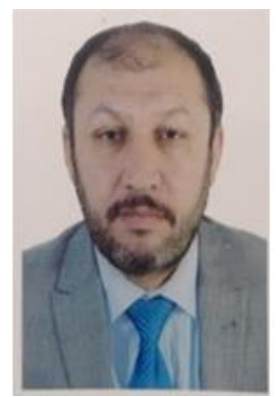

Wesam M. Jasim received the B.Sc. and M.Sc. degrees in control automation engineering from University of Technology, Baghdad, Iraq, and Ph.D. degree in computing and Electronics from University of Essex, Essex, UK. Currently, he is an Assistent Professor with the College of Computer Science and Information Technology, University of Anbar. His current research interests include robotics, multiagent systems, cooperative control, Robust control, linear and nonlinear control, Deep learning. He has published research papers at national and international journals, conference proceedings as well as chapters of book.

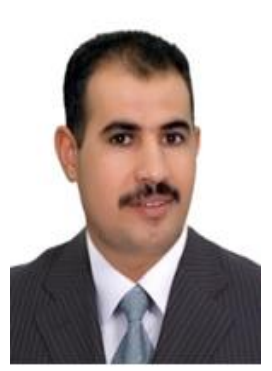

Yousif Ismail Mohammed Al Mashhadany is a lecturer in Electrical Engineering DepartmentCollege of Engineering (Control Engineering). Senior member IEEE, He received the B.Sc. (1995), M.Sc. (1999), and Ph.D (2010) in Department of Electrical and Electronic Engineering from the Rashid School of Engineering and Science / University of Technology in Baghdad/Iraq. He completes postdoctoral fellow research in electrical engineering - control department at the University of Malaya in Malaysia (UMPEDAC) in 2012. He works since 2004, a lecturer in the Department of Electrical Engineering / Engineering College / University of Anbar. He has many publishing that included three books, two chapters, thirty seven Journals paper most of them (Clarivate, Scopus and international journal), and thirty two conferences paper. 